\title{
Upregulation of nectin-4 is associated with ITGB1 and vasculogenic mimicry and may serve as a predictor of poor prognosis in colorectal cancer
}

\author{
JINXIU ZHANG, KECHENG LIU, PENG PENG, SIMAN LI, ZHE YE, \\ YINGJIE SU, SHIQUAN LIU, MENGBIN QIN and JIEAN HUANG \\ Department of Gastroenterology, The Second Affiliated Hospital of Guangxi Medical University, \\ Nanning, Guangxi 530007, P.R. China
}

Received July 1, 2018; Accepted May 2, 2019

DOI: $10.3892 / \mathrm{ol} .2019 .10417$

\begin{abstract}
Colorectal cancer (CRC) is one of the most common malignancies worldwide. Unlike endothelium-dependent vasculature, vasculogenic mimicry (VM) is an alternative type of blood supply in tumors that is frequently associated with poor patient outcome. Nectin- 4 serves a vital role in the formation and maintenance of adherens junctions; integrin $\beta-1$ (ITGB1) promotes tumor invasion, metastasis and VM formation. In the present study, the analysis of nectin-4 mRNA expression in a database of The Cancer Genome Atlas (TCGA) was combined with that of another non-overlapping cohort of 68 patients with CRC. TCGA data were used to examine nectin-4 mRNA expression in CRC and its correlation with the clinicopathological features of patients. Data from the non-overlapping cohort of patients was used to determine nectin- 4 and ITGB1 protein expression in CRC by immunohistochemical (IHC) staining. Cluster of differentiation 34/periodic acid-Schiff double staining was performed to validate the presence of VM formation. The association with, and significance of combining nectin-4,ITGB1 protein expression and VM formation for predicting patient prognosis was evaluated. The TCGA dataset demonstrated that nectin-4 mRNA was upregulated in CRC, which was significantly relate to lymph node metastasis $(\mathrm{P}=0.0017)$, distant metastasis $(\mathrm{P}=0.0045)$, and tumor-node-metastasis (TNM) stage $(\mathrm{P}=0.0015)$. Of the 68 patients analyzed by IHC staining, $48(70.6 \%)$ were positive for nectin- $4,46(67.6 \%)$ for ITGB1 and $17(25 \%)$ for VM formation. Nectin-4 protein expression was associated with ITGB1 protein expression $(\mathrm{P}<0.01)$ and
\end{abstract}

Correspondence to: Professor Jiean Huang or Dr Mengbin Qin, Department of Gastroenterology, The Second Affiliated Hospital of Guangxi Medical University, 166 Daxuedong Road, Nanning, Guangxi 530007, P.R. China

E-mail: hjagxmu@163.com

E-mail:dr.mmbin@hotmail.com

Key words: nectin-4, integrin $\beta-1$, vasculogenic mimicry, colorectal cancer, prognosis
VM formation $(\mathrm{P}<0.05)$. Nectin-4, ITGB1 expression and VM formation were associated with distant metastasis stage $(\mathrm{P}<0.05)$ and TNM stage $(\mathrm{P}<0.05)$. Based on these findings it was concluded that nectin-4 was upregulated in CRC tissues compared with normal mucosal tissues, and was associated with ITGB1 expression and VM formation. Furthermore, nectin-4 and ITGB1 protein expression, together with VM formation may be used to predict poor prognosis in CRC.

\section{Introduction}

Colorectal cancer (CRC) is one of the most common malignancies worldwide and the second most common cause of cancer-associated mortality (1). Despite advances in the treatment of CRC, the mortality rate of this disease remains high (2). Therefore, more reliable molecular prognostic markers are required to improve CRC diagnosis and treatment.

The nectin protein family belongs to the immunoglobulin superfamily, and its members are involved in the formation and maintenance of adherens junctions in cooperation with cadherin (3). At present, nectin-1, $-2,-3$ and -4 have been identified (3). Nectin-4 was originally described as a molecule homologous to the poliovirus receptor, also known as poliovirus receptor-like-4 (4). Unlike nectin-1 and -3 , which are widely expressed in the tissues of adults, nectin- 4 is largely restricted to embryonic and placental tissues (5). However, studies have indicated that tracheal tissue, skin and hair follicles express low levels of this protein $(5,6)$. In addition, a number of studies have revealed that nectin- 4 overexpression is fundamental for the invasion and metastasis of ovarian (7), breast (8), and lung cancer (9). The role of nectin-4 in cancer has not been extensively studied and its expression and prognostic value in CRC remains to be elucidated.

Integrins are cell membrane receptors that recognize and bind to the extracellular matrix and participate in multiple aspects of metastasis (10), including tumor angiogenesis (11). Furthermore, it has previously been reported that integrins are associated with another type of blood supply in tumors, vasculogenic mimicry (VM) (12-14). VM, which differs from classical tumor angiogenesis, is an alternative means of increasing the blood supply to tumors. In VM, tumor cells 
and a channel consisting of a basement membrane that stains positively to periodic acid-Schiff (PAS) are present; however this channel does not contain endothelial cells (15). It has been reported that VM, which is commonly observed in malignancies, is associated with poor differentiation, advanced clinical stage and poor prognosis (16). Further insight into the mechanisms of underlying the formation VM may provide novel insight for the development of anti-tumor therapy. A study demonstrated that short fibers and small pores in the matrix environment induce the formation of VM; specifically, an upregulation of the conserved transcription module has been reported in tumor cells, resulting in enhanced invasion and metastasis regulated by integrin $\beta-1$ (ITGB1) (14). Therefore, ITGB1 may serve a vital role in VM formation; however, further investigation is required.

The purpose of the present study was to evaluate the expression and prognostic value of nectin-4, ITGB1 and VM in CRC by performing a retrospective study based on data from The Cancer Genome Atlas (TCGA) cohort, and data obtained from another cohort of 68 non-overlapping patients with CRC.

\section{Materials and methods}

Bioinformatics analysis of TCGA data. Data for nectin-4 mRNA expression in CRC and normal tissues was downloaded from TCGA (https://cancergenome.nih.gov/) to examine the role of nectin- 4 expression in CRC and its association with the clinicopathological features of patients. A total of $372 \mathrm{CRC}$ samples and 31 normal samples from TCGA database were downloaded using the R package TCGA-Assembler 2.0 (17). This cohort of 372 patients with CRC consisted of 204 male and 168 female patients; 199 cases $\geq 65$ years old, $173<65$ years old; 282 were located in the colon, 90 were located in the rectum; 67 were Tumor-Node-Metastasis (TNM) I/TII stage, 304 were TNM III/TIV; 204 had no lymph node metastasis, 165 had lymph node metastases; 254 had no distant metastasis, and 50 had distant metastases.

Patients and tissue samples. The present study was approved by the Ethics committee of The First Affiliated Hospital of Guangxi Medical University (Nanning, China) and performed in accordance with the guidelines of the Declaration of Helsinki (no. BBMCEC2012063). All patients provided written informed consent to participate in the study. Between September 2013 and September 2016, a total of 68 CRC paraffin embedded tissues and 15 normal mucosal tissues were obtained from The First Affiliated Hospital of Guangxi Medical University. The cohort constituted 39 (57.4\%) males and $29(42.6 \%)$ females, and the median age of patients was 56 years (range, 26-81 years). Pathological staging was accorded to the National Comprehensive Cancer Network CRC classification (18). Detailed clinical and pathological data were also collected. Patients who had received preoperative chemo- or radiotherapy, or any other anti-cancer therapy were excluded from the study.

Immunohistochemical (IHC) staining and cluster of differentiation (CD)34/PAS dual staining. All tissue samples were fixed in $10 \%$ formalin for $24 \mathrm{~h}$ in room temperature and embedded in paraffin. Tissue sections (4-5 $\mu \mathrm{m})$ were

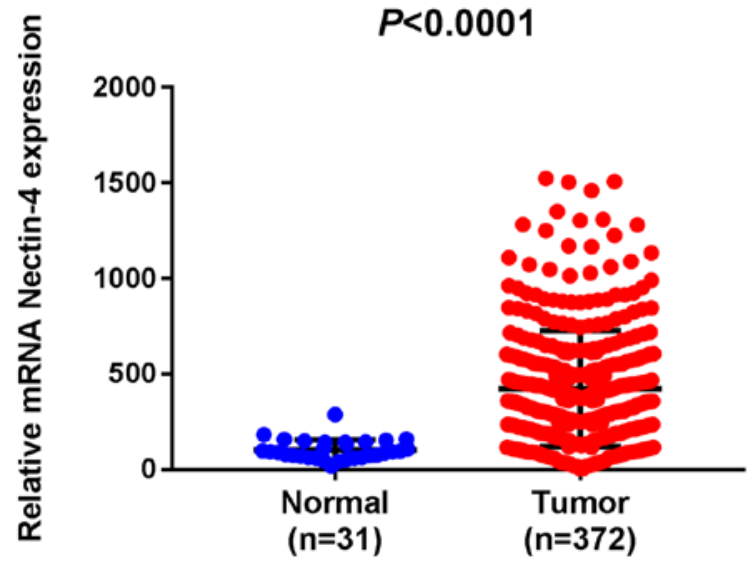

Figure 1. Nectin-4 mRNA expression in tumor and normal mucosal specimens, based on the data from The Cancer Genome Atlas database.

deparaffinized in xylene and rehydrated in ethanol (100, 95, 80 and $70 \%$ ), and slides were soaked in methanol (98\%), containing $3 \% \mathrm{H}_{2} \mathrm{O}_{2}$ for 10 min to block endogenous peroxidase activity. For antigen retrieval the slides were heated in the microwave for $30 \mathrm{~min}$ in citric acid buffer $(\mathrm{pH} \mathrm{6.4)}$. The slides were blocked with $10 \%$ normal goat serum (OriGene Technologies, Inc.) in PBS for $30 \mathrm{~min}$ at room temperature, and further incubated with primary antibodies for nectin-4 (cat. no. 21903-1-AP, 1:100, Proteintech Group, Inc., Chicago, IL, USA), ITGB1 (cat. no. 12594-1-AP, 1:200, Proteintech Group) and CD34 (cat. no. ZM-0046, OriGene Technologies, Inc.) at $4^{\circ} \mathrm{C}$ overnight. The following day the slides were incubated with appropriate horseradish peroxidase-conjugated secondary antibodies (OriGene Technologies, Inc.) for $30 \mathrm{~min}$ at room temperature. Visualization of the IHC reaction was performed using 3,3'-diaminobenzidine for $5 \mathrm{~min}$ at room temperature. After IHC staining of CD34, the sections were washed with running distilled water for $5 \mathrm{~min}$ and incubated with periodic acid for $20 \mathrm{~min}$ and Schiff reagent for $8 \mathrm{~min}$ at room temperature. CD34/PAS double-positive staining was used to characterize VM structures. Following staining with hematoxylin for $1 \mathrm{~min}$ at room temperature the slides were examined under an Olympus BX53 light microscope (magnification, x 200 and x400; Olympus Corporation, Tokyo, Japan).

IHC evaluation. The slides were independently evaluated by two pathologists, and IHC staining was quantified using the Remmele immunoreactive score (IRS). IRS=staining intensity (SI) x percentage of positive cells (PP). SI was defined as: i) 0 , Negative; ii) 1 , weak; iii) 2 , moderate; and iv) 3 , strong. PP was defined as: i) 0 , Negative; ii) $1,<25 \%$ positive cells; iii) $2,26-50 \%$ positive cells; iv) $3,51-75 \%$ positive cells; and v) $4,>75 \%$ positive cells. A total of ten visual fields from different areas of each tumor were used for IRS evaluation. The staining scoring system was defined as follows: i) 0 , Negative staining (-); ii) $1-4$ as weakly positive (1+); iii) 5-8 as moderately positive (2+); and iv) $9-12$ as strongly positive staining (3+). The negative and weakly positive categories $(-$ and $1+)$ were defined as negative, and moderate and strong positive categories $(2+$ and $3+)$ were recorded as positive results (19). 
A

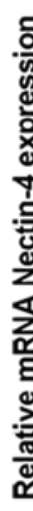

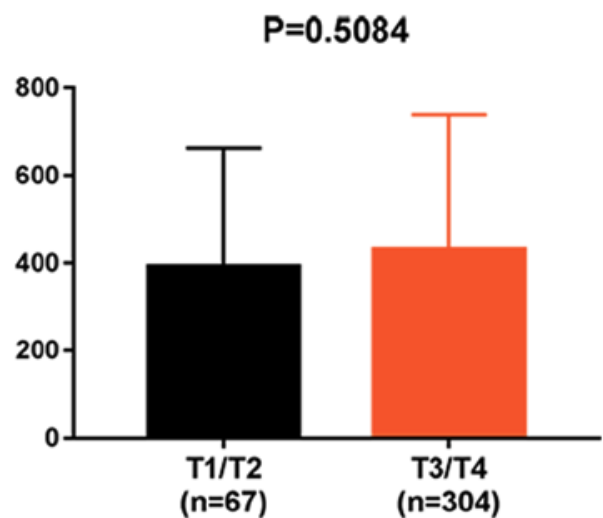

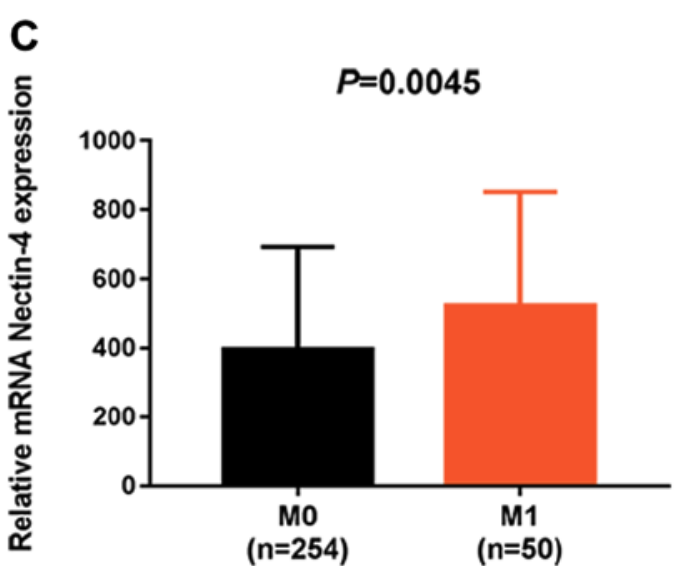

B

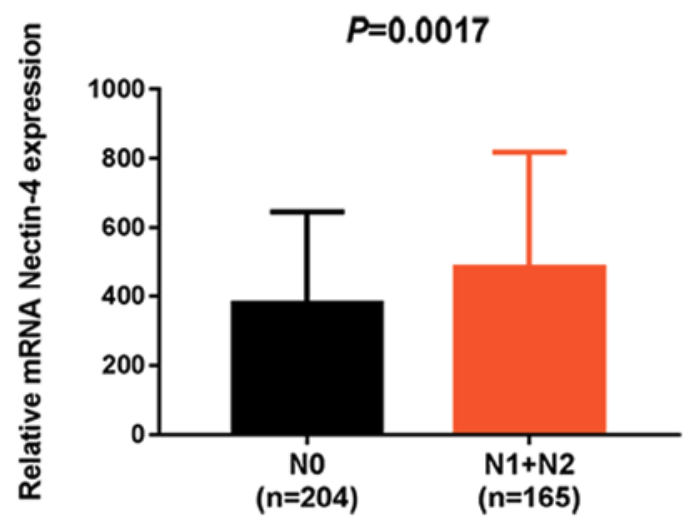

D

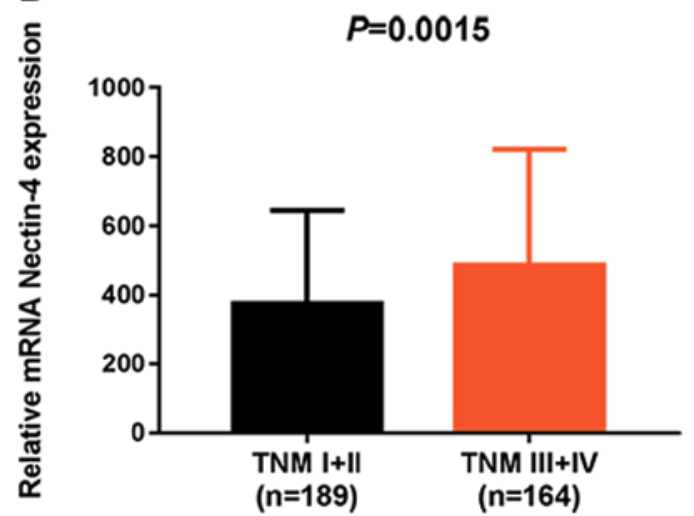

Figure 2. Nectin-4 mRNA expression is associated with various clinicopathological parameters. Based on the data from The Cancer Genome Atlas database, P-values were calculated using the t-test. Association between nectin-4 expression and (A) tumor stage (B) lymph node metastases, (C) distant metastasis stage, and (D) tumor node metastasis stage. T, tumor stage; $\mathrm{N}$ stage, lymph node metastasis stage; M stage, distant metastasis stage; TNM stage, Tumor-Node-Metastasis stage.

Statistical analysis. An independent sample t-test was used to compare continuous variables between CRC tissues and normal tissues. The $\chi^{2}$ test was used to determine the association between nectin-4, ITGB1 and VM formation. The association between nectin-4, ITGB1, VM formation and the clinicopathological parameters of patients was analyzed using the two-tailed $\chi^{2}$ test. All statistical analyses were performed using the SPSS software package (version 17.0; SPSS, Chicago, IL, USA), and $\mathrm{P}<0.05$ was considered to indicate a statistically significant difference.

\section{Results}

Upregulation of nectin-4 mRNA expression is associated with aggressive $C R C$. Nectin-4 mRNA expression data from 372 patients with $\mathrm{CRC}$, and 31 normal cases were downloaded from the TCGA database. P-values were calculated using the t-test. Nectin-4 mRNA expression in CRC tissues and normal mucosal tissues was analyzed. As presented in Fig. 1, nectin-4 mRNA expression was upregulated in CRC tissues compared with that in normal mucosal tissues $(\mathrm{P}<0.0001$; Fig. 1$)$. The association between nectin- 4 mRNA expression and patients' clinicopathological parameters were also assessed. Nectin-4 mRNA expression in tumor tissues was significantly associated with lymph node metastasis (N stage; Fig. 2B), distant metastasis (M stage, Fig. 2C) and advanced clinical stage
(TNM stage, Fig. 2D). By contrast, no significant differences were identified between nectin- 4 mRNA expression levels and tumor (T) stage (T stage, Fig. 2A), patient's age, tumor type, tumor site, presence of polyps (data not shown). Collectively these results suggested that the overexpression of nectin-4 mRNA was associated with the clinical progression of CRC.

Nectin-4 protein expression is higher in CRC tumors compared with normal mucosal tissues. To further confirm the results obtained from TCGA database analysis, a non-overlapping cohort of 68 patients with CRC were recruited, and nectin-4 protein expression levels were determined using IHC staining. A total of $68 \mathrm{CRC}$ and 15 normal mucosal tissue samples were collected. According to the National Comprehensive Cancer Network CRC classification, 7 patients were classified as stage I, 25 as stage II, 19 as stage III and 17 as stage IV. Consistent with the results obtained from the TCGA cohort, high nectin-4 protein expression was more frequently observed in tumor tissues when compared with normal tissues (Fig. 3). Only $3(20 \%)$ normal mucosal samples displayed high nectin-4 protein expression levels, while $48(70.6 \%)$ of the CRC tissues displayed high levels (Table I, $\mathrm{P}<0.01$ ).

Association between nectin-4, ITGB1 and VM formation in $C R C$. In addition to nectin-4 protein expression, the expression of ITGB1 and VM formation were also determined. Of 

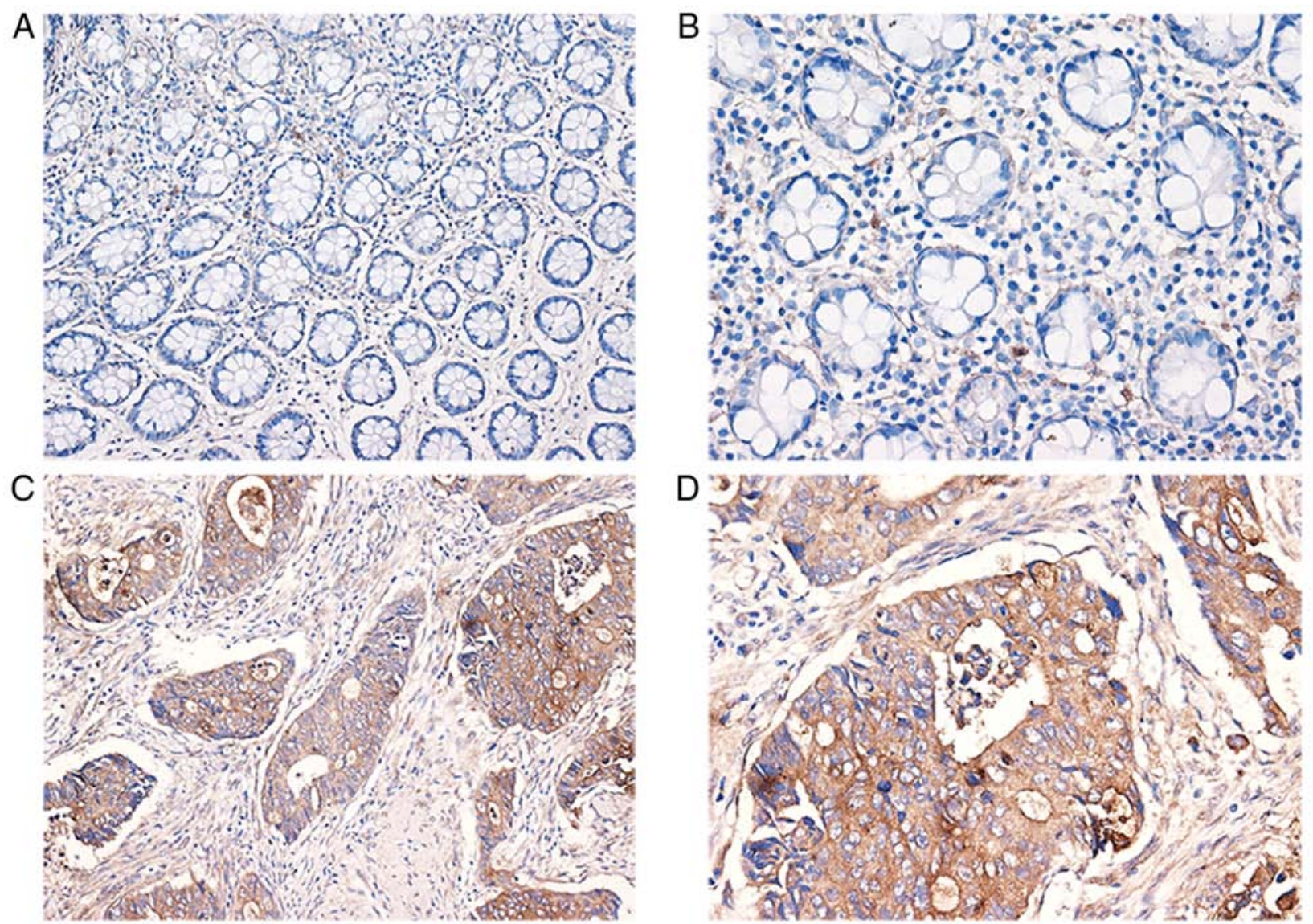

Figure 3. Nectin-4 protein expression in normal colorectal mucosal tissue, and colorectal cancer tissue. Normal colorectal mucosal tissue: Magnifications, (A) $\times 200$ and (B) 400. Colorectal cancer tissue: Magnifications, (C) x200 and (D) 400 .

the 68 cases analyzed, $48(70.6 \%)$ were positive for nectin- 4 protein expression, $46(67.6 \%)$ were positive for ITGB1 protein expression and in $17(25 \%)$ cases, VM formation was observed (Table II). Nectin-4 and ITGB1 protein expression were higher in later TNM stages (TNM III and IV) compared with early cancer stages (TNM I and II; Fig. 4). Notably, statistical analysis revealed that nectin-4 was positively associated with ITGB1 expression (Table II). CD34/PAS double staining was used to detect VM formation. Structures characterized by $\mathrm{CD} 34 / \mathrm{PAS}^{+}$staining, with red blood cells in the vascular-like tube, and surrounded by tumor cells, were identified as VM (Fig. 5, red arrow). Structures with CD34 ${ }^{+}$ and $\mathrm{PAS}^{+}$staining were identified as endothelium dependent vasculature (Fig. 4, black arrow). Statistical analysis revealed that nectin-4 protein expression was positively associated with VM formation (Table II).

Associations between nectin-4, ITGBI and VM, and the clinicopathological parameters of patients with $C R C$. To evaluate the influences of nectin-4, ITGB1, and VM on CRC, the obtained results were further compared with patient clinicopathological characteristics. The expression of nectin-4 (48/68, $70.6 \%)$ and ITGB1 $(46 / 68,67.6 \%)$, in addition to VM formation 17/68, 25\%), were all positively associated with distant metastasis stage ( $\mathrm{M}$ stage; $\mathrm{P}=0.031, \mathrm{P}=0.017$, and $\mathrm{P}=0.034$, respectively), TNM stage $(\mathrm{P}=0.033, \mathrm{P}=0.020$, and $\mathrm{P}=0.023$, respectively), but not with patient sex, age, tumor size or lymph node metastasis stage ( $\mathrm{N}$ stage; Table III). Compared with the early stages (TNM I and II), the expression of nectin-4 and ITGB1, and VM formation were more frequently observed in the later stages of CRC (TNM III and IV). These results indicated that nectin-4 and ITGB1 protein expression, and VM formation were positively associated with CRC progression and may be indicators of poor prognosis.

\section{Discussion}

$\mathrm{CRC}$ is a common gastrointestinal malignancy with a high incidence of metastasis. Once metastasis occurs, the outcomes of surgery, radiotherapy or chemotherapy on patient prognosis are unsatisfactory, and the mortality rate remains high. Therefore the identification of novel molecular prognostic and predictive markers is required.

Nectin-4, a cell adhesion molecule that interacts with the cadherins, serves a key role in the formation and maintenance of adherens junctions $(6,20)$. Nectin- 4 consists of three immunoglobulin-like domains, which constitute transmembrane and extracellular domains, and a short cytoplasmic tail (20). It has been reported that nectin-4 promotes the anchorage-independent growth of human mammary epithelial cells by driving cell-to-cell attachment and activating integrin $\beta 4 /$ Src homology region 2-containing protein tyrosine phosphatase $2 / \mathrm{c}$-Src signaling (21). In addition, nectin-4 regulates epithelial-mesenchymal transition, tumor invasion 
Table I. Nectin-4 expression in colorectal cancer and normal mucosal tissues.

\begin{tabular}{|c|c|c|c|}
\hline Immunohistochemical staining & Colorectal cancer tissues $n=68(\%)$ & Normal tissues $\mathrm{n}=15(\%)$ & P-value \\
\hline Negative (-) & $20(29.4)$ & $12(80)$ & $0.001^{\mathrm{a}}$ \\
\hline Positive (+) & $48(70.6)$ & $3(20)$ & \\
\hline
\end{tabular}

${ }^{\mathrm{a}} \mathrm{P}<0.01$, as determined by a $\chi^{2}$ test.

Table II. Correlation between nectin-4 and ITGB1 or VM in colorectal cancer.

\begin{tabular}{|c|c|c|c|c|c|c|c|c|}
\hline \multirow[b]{2}{*}{ Nectin-4 (n) } & \multicolumn{2}{|c|}{ ITGB1 (n) } & \multirow[b]{2}{*}{$\chi^{2}$ value } & \multirow[b]{2}{*}{ P-value } & \multicolumn{2}{|c|}{ VM (n) } & \multirow[b]{2}{*}{$\chi^{2}$-value } & \multirow[b]{2}{*}{ P-value } \\
\hline & - & + & & & - & + & & \\
\hline- & 17 & 3 & 32.556 & $<0.001^{\mathrm{b}}$ & 19 & 1 & 4.628 & $0.014^{\mathrm{a}}$ \\
\hline+ & 5 & 43 & & & 32 & 16 & & \\
\hline
\end{tabular}

${ }^{\mathrm{a}} \mathrm{P}<0.05$ and ${ }^{\mathrm{b}} \mathrm{P}<0.01$, as determined by a $\chi^{2}$ test.
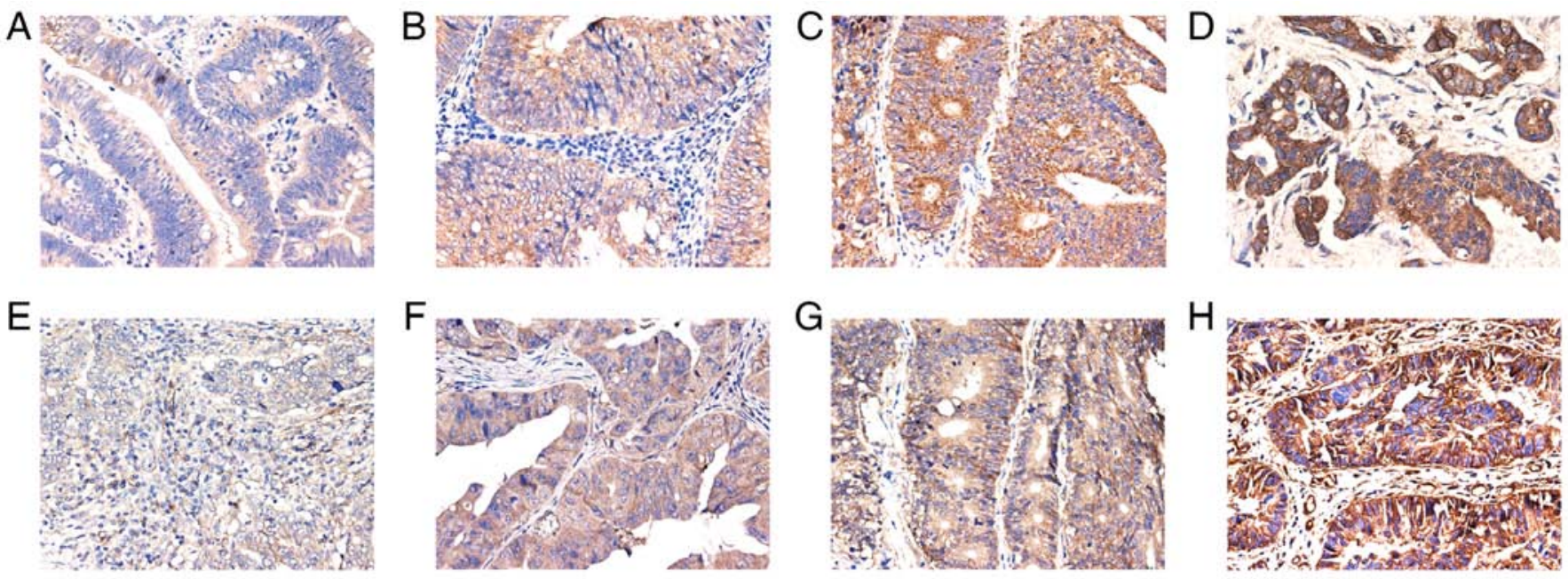

Figure 4. Immunohistochemical analysis of nectin-4 and ITGB1 protein expression in CRC tissues (magnification, x400). (A-D) Nectin-4 and (E-H) ITGB1 protein expression were higher in the later stages of CRC (TNM III and TNM IV, C-D, G-H) compared with the early stages (TNM I and TNM II, A-B, E-F). CRC, colorectal cancer; ITGB1, Integrin $\beta-1$; TNM, tumor node metastasis.

and metastasis in breast cancer through its influence on the Wnt/ $\beta$-catenin signaling pathway and the phosphoinositide 3-kinase/protein kinase B signaling axis (22). In non-small cell lung cancer, nectin-4 promotes tumor invasion and metastasis by activating the Rho-related protein racL (10). Furthermore, it has been reported that VM, as an alternative blood supply to tumors, is associated with a malignant phenotype and poor patient prognosis (23-25). Traditional anti-angiogenic therapy is aimed at endothelium-dependent blood vessels. Although this treatment delays the progression of tumors in a short period of time, recurrence and metastasis are issues for a number of patients (26). Therefore, further insight into the mechanisms of VM may aid developments in the field of anti-tumor therapeutics. Recent studies have reported that
ITGB1 may promote proliferation, invasion and metastasis in a variety of tumor types, and may therefore be associated with poor prognosis $(27,28)$. Additional studies have also revealed that ITGB1 is crucial for the formation of VM, where ITGB1 promoted migrational persistence and influenced the shape of VM structures by regulating specific aspects of the transcriptional module associated with the VM network-forming phenotype (15).

In the present study, nectin- 4 mRNA expression data from 372 patients with CRC were downloaded from a TCGA database. In this cohort, the overexpression of nectin-4 mRNA was strongly associated with lymphatic metastasis, distant metastasis and TNM classification. Collectively these findings suggest that nectin-4 overexpression is associated with 
Table III. Relationship between nectin-4, ITGB1, VM and clinicopathological features in colorectal cancer.

\begin{tabular}{|c|c|c|c|c|c|c|c|c|c|}
\hline \multirow[b]{2}{*}{ Characteristics } & \multicolumn{2}{|c|}{ Nectin-4 } & \multirow[b]{2}{*}{$\mathrm{P}$-value } & \multicolumn{2}{|c|}{ ITGB1 } & \multirow[b]{2}{*}{ P-value } & \multicolumn{2}{|c|}{ VM } & \multirow[b]{2}{*}{ P-value } \\
\hline & - & + & & - & + & & - & + & \\
\hline \multicolumn{10}{|l|}{ Sex } \\
\hline Male & 10 & 28 & 0.528 & 11 & 27 & 0.499 & 24 & 11 & 0.207 \\
\hline Female & 10 & 20 & & 11 & 19 & & 27 & 6 & \\
\hline \multicolumn{10}{|l|}{ Age } \\
\hline$\geq 65$ & 5 & 15 & 0.403 & 6 & 14 & 0.789 & 16 & 4 & 0.760 \\
\hline$<65$ & 17 & 31 & & 16 & 32 & & 35 & 13 & \\
\hline \multicolumn{10}{|l|}{ Size (cm) } \\
\hline$\geq 5.0$ & 10 & 25 & 0.876 & 9 & 26 & 0.344 & 25 & 8 & 0.889 \\
\hline$<5.0$ & 10 & 23 & & 13 & 20 & & 26 & 9 & \\
\hline \multicolumn{10}{|l|}{$\mathrm{N}$ stage } \\
\hline No & 13 & 27 & 0.504 & 14 & 26 & 0.577 & 30 & 10 & 0.909 \\
\hline $\mathrm{N} 1+\mathrm{N} 2$ & 7 & 21 & & 8 & 20 & & 21 & 7 & \\
\hline \multicolumn{10}{|l|}{ M stage } \\
\hline M0 & 19 & 32 & $0.031^{\mathrm{a}}$ & 21 & 30 & $0.017^{\mathrm{a}}$ & 42 & 9 & $0.034^{\mathrm{a}}$ \\
\hline M1 & 1 & 16 & & 1 & 16 & & 11 & 8 & \\
\hline \multicolumn{10}{|l|}{ TNM stage } \\
\hline $\mathrm{I}+\mathrm{II}$ & 14 & 20 & $0.033^{\mathrm{a}}$ & 16 & 18 & $0.020^{\mathrm{a}}$ & 30 & 4 & $0.023^{\mathrm{a}}$ \\
\hline III + IV & 6 & 28 & & 6 & 28 & & 21 & 13 & \\
\hline
\end{tabular}

${ }^{\text {a }} \mathrm{P}<0.05$, as determined by two-tailed $\chi^{2}$ test. $\mathrm{N}$ stage, lymph node metastasis stage; $\mathrm{M}$ stage, distant metastasis stage; TNM stage, tumor node metastasis stage; ITGB, integrin $\beta-1 ; \mathrm{VM}$, vasculogenic mimicry.
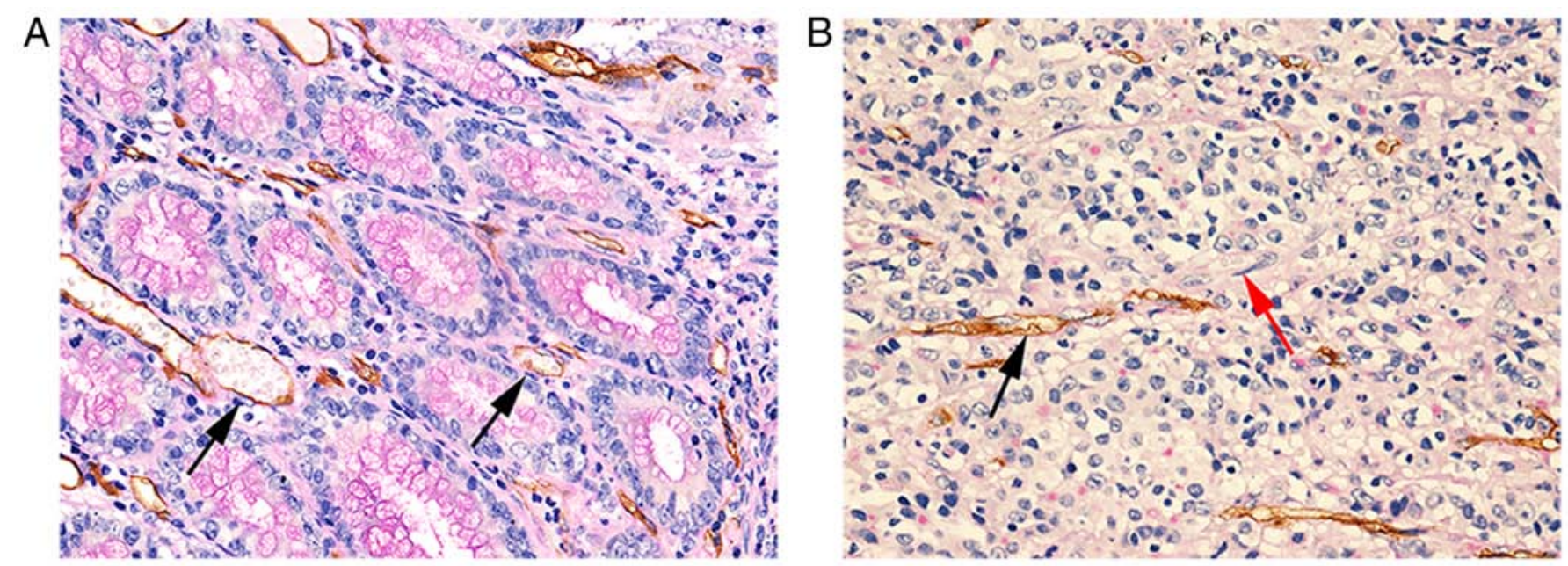

Figure 5. Identifying endothelium-dependent vessels and VM by cluster of differentiation 34/periodic acid-Schiff double staining. (A) VM negative staining in CRC tissue (magnification, x400). The black arrow indicates an endothelium-dependent vessel. (B) VM positive staining in CRC tissue (magnification, $\mathrm{x} 400$. The red arrow indicates a VM structure, and the black arrow indicates endothelium-dependent vasculature. VM, vasculogenic mimicry; CRC, colorectal cancer.

the progression of $\mathrm{CRC}$, which is consistent with findings for nectin- 4 expression in other tumor types $(8,29)$. To further confirm the results obtained from the TCGA cohort, nectin- 4 protein expression was assessed using IHC staining in a separate cohort of patients. The results revealed that nectin- 4 protein expression was significantly upregulated in CRC tissues compared with normal mucosal tissues. In addition, an association between nectin-4, and ITGB1 protein expression and VM formation was observed in this cohort. Positive IHC staining results for these parameters were associated with $\mathrm{M}$ and TNM stage, but not patient sex, age, tumor size or N stage. Therefore, the results of the present study suggested that the 
expression of nectin-4 and ITGB1, and VM formation may facilitate the progression of CRC.

In conclusion, we aimed to combine the data obtained from a TCGA database with that obtained from a separate patient cohort in order to examine nectin- 4 expression at the mRNA and protein levels. The results concluded that nectin- 4 was upregulated in CRC tissues compared with normal mucosal tissues, and that nectin-4 expression was positively associated with ITGB1 expression and VM formation. Furthermore, all three parameters (nectin-4, ITGB1 and VM) were significantly associated with $\mathrm{M}$ and TNM stage, characteristic features of highly invasive CRCs. Therefore, nectin-4, ITGB1 and VM combined may be useful in identifying the progression of CRC I patients, and those with poor prognosis.

\section{Acknowledgements}

Not applicable.

\section{Funding}

The present study was supported by grants from the National Natural Science Foundation of China (grant no. 81760516), the 2018 Innovation Project of Guangxi Graduate Education (grant no. YCBZ2018046) and the Guangxi Zhuang Autonomous Region Health and Family Planning Commission Self-financing research projects (grant no. Z20170086).

\section{Availability of data and materials}

The datasets used and/or analyzed during the current study are available from the corresponding author on reasonable request.

\section{Authors' contributions}

JZ contributed to the study design, data analysis and drafted the manuscript. KL and YS performed the experiments and the bioinformatics analysis. PP and ShL contributed to the clinical data acquisition and analysis. SiL and ZY performed the experiments. MQ and JH contributed to the study design, reviewed and edited the manuscript. All authors have read and approved the final manuscript.

\section{Ethics approval and consent to participate}

The present study was approved by the Ethics committee of the First Affiliated Hospital of Guangxi Medical University, and performed in accordance with the guidelines of the Declaration of Helsinki (no. BBMCEC2012063). All patients admitted to the study provided written informed consent for their participation.

\section{Patient consent for publication}

All patients admitted to the study provided informed consent for their participation and publication of the data.

\section{Competing interests}

The authors declare that they have no competing interests.

\section{References}

1. Siegel RL, Miller KD and Jemal A: Cancer statistics, 2017. CA Cancer J Clin 67: 7-30, 2017.

2. Miller KD, Siegel RL, Lin CC, Mariotto AB, Kramer JL, Rowland JH, Stein KD, Alteri R and Jemal A: Cancer treatment and survivorship statistics, 2016. CA Cancer J Clin 66: 271-289, 2016.

3. Takai Y, Miyoshi J, Ikeda W and Ogita H: Nectins and nectin-like molecules: Roles in contact inhibition of cell movement and proliferation. Nature reviews. Nat Rev Mol Cell Biol 9: 603-615, 2008.

4. Rajc J, Gugić D, Fröhlich I, Marjanović K and Dumenčić B: Prognostic role of Nectin-4 expression in luminal B (HER2 negative) breast cancer. Pathol Res Pract 213: 1102-1108, 2017.

5. Reymond N, Fabre S, Lecocq E, Adelaide J, Dubreuil P and Lopez M: Nectin4/PRR4, a new afadin-associated member of the nectin family that trans-interacts with nectin1/PRR1 through V domain interaction. J Biol Chem 276: 43205-43215, 2001.

6. Brancati F, Fortugno P, Bottillo I, Lopez M, Josselin E, Boudghene-Stambouli O, Agolini E, Bernardini L, Bellacchio E, Iannicelli M, et al: Mutations in PVRL4, encoding cell adhesion molecule nectin-4, cause ectodermal dysplasia-syndactyly syndrome. Am J Hum Genet 87: 265-273, 2010.

7. Derycke MS, Pambuccian SE, Gilks CB, Kalloger SE, Ghidouche A, Lopez M, Bliss RL, Geller MA, Argenta PA, Harrington KM and Skubitz AP: Nectin 4 overexpression in ovarian cancer tissues and serum: Potential role as a serum biomarker. Am J Clin Pathol 134: 835-845, 2010.

8. Fabre-Lafay S, Monville F, Garrido-Urbani S, Berruyer-Pouyet C, Ginestier C, Reymond N, Finetti P, Sauvan R, Adélaïde J, Geneix J, et al: Nectin-4 is a new histological and serological tumor associated marker for breast cancer. BMC Cancer 7: 73, 2007.

9. Takano A, Ishikawa N, Nishino R, Masuda K, Yasui W, Inai K, Nishimura H, Ito H, Nakayama H, Miyagi Y, et al: Identification of nectin-4 oncoprotein as a diagnostic and therapeutic target for lung cancer. Cancer Res 69: 6694-6703, 2009.

10. Bianconi D, Unseld M and Prager GW: Integrins in the spotlight of cancer. Int J Mol Sci 17: pii: E2037, 2016.

11. Duro-Castano A, Gallon E, Decker C and Vicent MJ: Modulating angiogenesis with integrin-targeted nanomedicines. Adv Drug Deliv Rev 119: 101-119, 2017.

12. Vartanian A, Stepanova E, Grigorieva I, Solomko E, Belkin V, Baryshnikov A and Lichinitser M: Melanoma vasculogenic mimicry capillary-like structure formation depends on integrin and calcium signaling. Microcirculation 18: 390-399, 2011.

13. Camorani S, Crescenzi E, Gramanzini M, Fedele M, Zannetti A and Cerchia L: Aptamer-mediated impairment of EGFR-integrin $\alpha v \beta 3$ complex inhibits vasculogenic mimicry and growth of triple-negative breast cancers. Sci Rep 7: 46659, 2017.

14. Velez DO, Tsui B, Goshia T, Chute CL, Han A, Carter H and Fraley SI: 3D collagen architecture induces a conserved migratory and transcriptional response linked to vasculogenic mimicry. Nat Commun 8: 1651, 2017.

15. Maniotis AJ, Folberg R, Hess A, Seftor EA, Gardner LM, Pe'er J, Trent JM, Meltzer PS and Hendrix MJ: Vascular channel formation by human melanoma cells in vivo and in vitro: Vasculogenic mimicry. Am J Pathol 155: 739-752, 1999.

16. Qiao L, Liang N, Zhang J, Xie J, Liu F, Xu D, Yu X and Tian Y: Advanced research on vasculogenic mimicry in cancer. J Cell Mol Med 19: 315-326, 2015.

17. Wei L, Jin Z, Yang S, Xu Y, Zhu Y and Ji Y: TCGA-assembler 2: Software pipeline for retrieval and processing of TCGA/CPTAC data. Bioinformatics 34: 1615-1617, 2018.

18. Benson AB III, Venook AP, Cederquist L, Chan E, Chen YJ, Cooper HS, Deming D, Engstrom PF, Enzinger PC, Fichera A, et al: Colon cancer, version 1.2017, NCCN clinical practice guidelines in oncology. J Natl Compr Canc Netw 15: 370-398, 2017.

19. Sadeghi MR, Jeddi F, Soozangar N, Somi MH, Shirmohamadi M, Khaze V and Samadi N: Nrf2/P-glycoprotein axis is associated with clinicopathological characteristics in colorectal cancer. Biomed Pharmacother 104: 458-464, 2018.

20. Kurita S, Ogita $\mathrm{H}$ and Takai Y: Cooperative role of nectin-nectin and nectin-afadin interactions in formation of nectin-based cell-cell adhesion. J Biol Chem 286: 36297-36303, 2011.

21. Pavlova NN, Pallasch C, Elia AE, Braun CJ, Westbrook TF, Hemann M and Elledge SJ: A role for PVRL4-driven cell-cell interactions in tumorigenesis. ELife 2: e00358, 2013.

22. Siddharth S, Goutam K, Das S, Nayak A, Nayak D, Sethy C, Wyatt MD and Kundu CN: Nectin- 4 is a breast cancer stem cell marker that induces WNT/ $\beta$-catenin signaling via Pi3k/Akt axis. Int J Biochem Cell Biol 89: 85-94, 2017. 
23. Cao Z, Bao M, Miele L, Sarkar FH, Wang Z and Zhou Q Tumour vasculogenic mimicry is associated with poor prognosis of human cancer patients: A systemic review and meta-analysis. Eur J Cancer 49: 3914-3923, 2013.

24. Zhang J, Qiao L, Liang N, Xie J, Luo H, Deng G and Zhang J: Vasculogenic mimicry and tumor metastasis. J BUON 21: 533-541, 2016.

25. Sun B, Zhang D, Zhao N and Zhao X: Epithelial-to-endothelial transition and cancer stem cells: Two cornerstones of vasculogenic mimicry in malignant tumors. Oncotarget 8: 30502-30510, 2017.

26. Dey N, De P and Brian LJ: Evading anti-angiogenic therapy: Resistance to anti-angiogenic therapy in solid tumors. Am J Transl Res 7: 1675-1698, 2015.

27. Chen MB, Lamar JM, Li R, Hynes RO and Kamm RD: Elucidation of the roles of tumor integrin betal in the extravasation stage of the metastasis cascade. Cancer Res 76: 2513-2524, 2016.
28. Xu Z, Zou L, Ma G, Wu X, Huang F, Feng T, Li S, Lin Q, He X, Liu $Z$ and Cao $X$ : Integrin $\beta 1$ is a critical effector in promoting metastasis and chemo-resistance of esophageal squamous cell carcinoma. Am J Cancer Res 7: 531-542, 2017.

29. Zhang Y, Liu S, Wang L, Wu Y, Hao J, Wang Z, Lu W, Wang XA, Zhang F, Cao Y, et al: A novel PI3K/AKT signaling axis mediates Nectin-4-induced gallbladder cancer cell proliferation, metastasis and tumor growth. Cancer Lett 375: 179-189, 2016.

(i) (9) This work is licensed under a Creative Commons

EY NG ND Attribution-NonCommercial-NoDerivatives 4.0 International (CC BY-NC-ND 4.0) License. 